\title{
Relative Efficiency And Quality Of Global Automobile Companies
}

Seetharama L. Narasimhan, (E-mail: narasimhan@uri.edu), University of Rhode Island Allan W. Graham, University of Rhode Island

Mulong Wang, University of Rhode Island

\begin{abstract}
We investigate global automobile companies to determine whether quality and productivity are associated with profitability and increased market share. From multiple tests, evidence suggests that 1) the firms fall into three groups: Toyota and Honda excel in all categories and are in the high performing group; Audi, GM, Mazda, BMW, and Nissan are in a moderate performing group while Daimler/Chrysler, Ford, Mitsubishi and Volkswagen are in a relatively low performing group; 2) that firms with high (low) quality, on average, have higher (lower) profitability and higher (lower) increases in market share for the sample period. Implications for managers of manufacturing firms with a consumer market presence is that firms that pursue product quality and value to their customers should benefit by improved financial performance.
\end{abstract}

\section{INTRODUCTION}

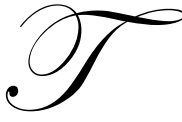

he automotive industry operates in a very competitive environment managed by multinational firms from Europe, Asia and the United States. Motivated by several articles in the popular press on performance in the automotive industry, and by the lack of comprehensive analysis and research in this area, we compare the efficiency and productivity of global automotive companies using Data Envelopment Analysis (hereafter, DEA). It is an important topic to address because the automotive and its ancillary industries comprise $\$ 423.4$ billion of the $\$ 10.48$ trillion the U.S. GDP (Government Publications, 2002).

The role of quality is often stressed by change experts Deming, Juran, Crosby and Taguchi (Mitra, 1993). They assert that attention to quality can increase revenues by improving a company's response to its customers. Ancillary gains for firms that pursue a quality agenda include the possibility of charging higher prices, improving reputation while reducing the total cost of products through increased productivity, lower rework, setup, and warranty costs. Skinner (1985) advocates four dimensions: price, quality, reliability, and support as a competitive weapon to enhancing and increasing productivity in manufacturing industries.

The DEA methodology developed by Charnes, et al., (1978) defines a nonparametric relationship between multiple outputs and multiple inputs and specifies that an efficient frontier consists of the most efficient decisionmaking units (DMU). Firms that have a relative efficiency of 1 lie along the efficient frontier and firms that have relative efficiency something less than 1 lie inside the efficient frontier. The procedure is based on the notion that no other unit or linear combinations of units can generate the same amount of outputs for the given inputs (Charnes, et. al., 1994). The solution procedure to solve the DEA model as developed by Ali, et. al. (1993) and related literature is shown in Appendix A.

We select inputs and outputs from publicly available financial operating data and from various online sources. Similar to Chapman, we use annualized data. The automotive supply chain consists of suppliers, manufacturing operations as well as sales and service by the dealers, with service being a large component the process. Soteriou and Stavrinides (1997), Lothgren and Tambour (1999), and Brown and Ragsdale (2002), use consumer satisfaction as an output in service operations situations. Hence, consumer satisfaction is likely an important goal of automotive firms. 
Consequently, we use consumer satisfaction as an output, in addition to the financial operating data. We use the consumer satisfaction scores reported in Consumer Reports, which is based on questionnaires they distribute to sample consumers. Their scale from 1 to 5 (with 5 being the highest rating) is based on a response to the question "Would you buy this particular vehicle again?" In summary, for our examination of the automobile industry, we use total revenue, net income, and a quality measure - consumer satisfaction- as outputs, and use cost of sales in addition to selling, general and administrative expenses as inputs. Our DEA model parameters are detailed in Figure 1.

Figure 1: Specification of Outputs and Inputs for the DEA Model

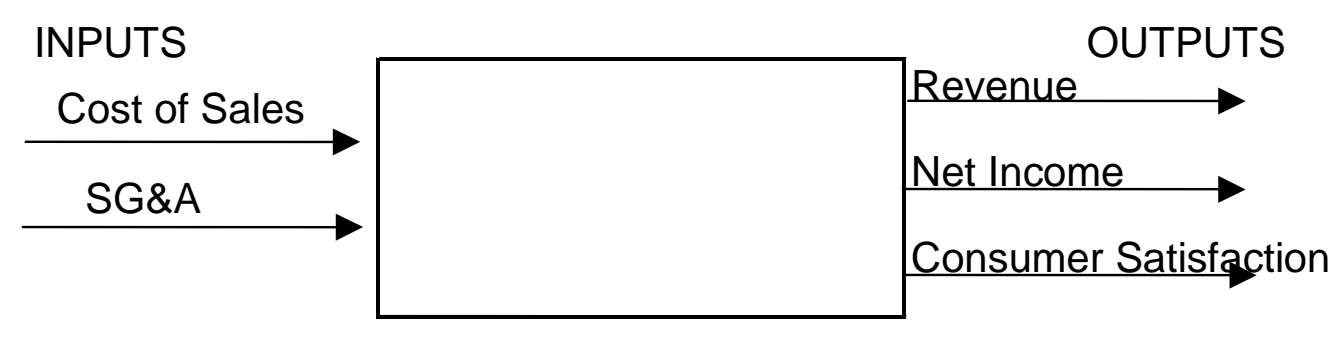

\section{Sample Firms and Data}

The sample firms are: Audi (A) BMW (B), Daimler/Chrysler (D), Ford (F) GM (G), Honda (H), Mazda (Ma), Mitsubishi (Mi), Nissan (N), Toyota (T) and Volkswagen (V). The sample firms are found in the Market Share Reporter, which lists the top worldwide automakers ( Lazich 1998-2003). We deleted some firms listed in Market Share Reporter (Renault, Hyundai Motor Corporation, Fiat Auto S.P.A and PSA Peugeot Citron, Isuzu and Subaru) from our analysis because current detailed financial data are not available from online resources.

The comparative DEA efficiencies for years 1998 through 2003 were computed using the specified input and output data downloaded from Mergent Online (1998-2003) and Consumer Reports (1998-2003). Table 1 exhibits the inputs and outputs for computing the DEA efficiency calculations for the year 2003.

Table 1: DEA data and Solution Layout for 2003

The sample firms are: Audi (A), BMW (B), Daimler/Chrysler (D), Ford (F), GM (G), Honda (H), Mazda (Ma), Mitsubishi (Mi), Nissan (N), Toyota (T) and Volkswagen (V).

\begin{tabular}{|c|c|c|c|c|c|c|c|c|c|}
\hline \multirow[b]{2}{*}{ Company } & \multirow[b]{2}{*}{ Revenue } & \multicolumn{2}{|c|}{ OUTPUTS } & \multicolumn{2}{|c|}{ INPUTS } & \multirow{2}{*}{$\begin{array}{c}\text { Weighted } \\
\text { Output }\end{array}$} & \multirow{2}{*}{$\begin{array}{l}\text { Weighted } \\
\text { Input }\end{array}$} & \multirow[b]{2}{*}{ Difference } & \multirow{2}{*}{$\begin{array}{c}\text { DEA } \\
\text { Efficiency }\end{array}$} \\
\hline & & Net Income & Satisfy & C/G/S & SG\&A & & & & \\
\hline $\mathrm{A}$ & 23406 & 816 & 3.5 & 21199 & 1703 & 0.19122 & 0.19122 & 0 & 1 \\
\hline B & 51611 & 2420 & 4.83 & 39885 & 5526 & 0.42164 & 0.42164 & 0 & 1 \\
\hline $\mathrm{D}$ & 169578 & 557 & 2.56 & 136627 & 22089 & 1.38538 & 1.52853 & -0.14315 & 0.94833 \\
\hline $\mathrm{F}$ & 138442 & 490 & 2.43 & 129821 & 10152 & 1.13101 & 1.16362 & -0.0326 & 0.99221 \\
\hline $\mathrm{G}$ & 185524 & 3822 & 2.48 & 152071 & 21008 & 1.51565 & 1.60597 & -0.09032 & 0.94376 \\
\hline $\mathrm{H}$ & 76728 & 4365 & 5 & 52732 & 14135 & 0.62684 & 0.73943 & -0.1126 & 1 \\
\hline $\mathrm{Ma}$ & 27412 & 319 & 3 & 20353 & 6399 & 0.22394 & 0.31054 & -0.08659 & 1 \\
\hline $\mathrm{Mi}$ & 23683 & -2025 & 3 & 20310 & 4284 & 0.19348 & 0.25388 & -0.0604 & 0.9476 \\
\hline $\mathrm{N}$ & 69835 & 4734 & 3 & 49961 & 12165 & 0.57052 & 0.66787 & -0.09735 & 1 \\
\hline$T$ & 162571 & 10924 & 4.5 & 126960 & 19942 & 1.32814 & 1.40482 & -0.07668 & 1 \\
\hline $\mathrm{V}$ & 108322 & 1361 & 4 & 96640 & 12578 & 0.88495 & 1 & -0.11505 & 0.89595 \\
\hline
\end{tabular}

The objective is to maximize the weighted sum of outputs with those defined constraints and, therefore, it is equivalent to solving eleven linear programming problems. We use Microsoft EXCEL to build a visual basic subroutine and simultaneously compute the DEA efficiencies for all automotive companies (Ragsdale, 2004). The results for the six-year data are presented in Table 2 below. 
Table 2: Comparison of DEA Efficiencies

The sample firms are: Audi (A), BMW (B), Daimler/Chrysler (D), Ford (F), GM (G), Honda (H), Mazda (Ma), Mitsubishi (Mi), Nissan (N), Toyota (T) and Volkswagen (V).

\begin{tabular}{|l|r|r|r|r|r|r|}
\hline Company & 2003 & 2002 & 2001 & 2000 & 1999 & 1998 \\
\hline $\mathrm{A}$ & 1 & 1 & 1 & 1 & 1 & 1 \\
\hline $\mathrm{B}$ & 1 & 1 & 1 & 0.79 & 0.91 & 0.82 \\
\hline $\mathrm{D}$ & 0.95 & 0.88 & 0.86 & 1 & 0.97 & 1 \\
\hline $\mathrm{F}$ & 0.99 & 0.96 & 0.89 & 0.71 & 1 & 1 \\
\hline $\mathrm{G}$ & 0.94 & 0.98 & 0.9 & 0.67 & 1 & 1 \\
\hline $\mathrm{H}$ & 1 & 1 & 1 & 1 & 1 & 1 \\
\hline $\mathrm{Ma}$ & 1 & 1 & 1 & 0.72 & 1 & 1 \\
\hline $\mathrm{Mi}$ & 0.95 & 1 & 0.94 & 0.67 & 0.96 & 1 \\
\hline $\mathrm{N}$ & 1 & 1 & 1 & 1 & 0.96 & 0.99 \\
\hline $\mathrm{T}$ & 1 & 1 & 0.94 & 1 & 1 & 1 \\
\hline $\mathrm{V}$ & 0.9 & 0.88 & 0.89 & 0.77 & 0.91 & 0.92 \\
\hline
\end{tabular}

The results indicate that for the year 2003, Audi, BMW, Honda, Mazda, Nissan and Toyota have a relative efficiency score of one. It is important to note that even if all companies had a loss in any particular year, the program computes the relative efficiencies (not absolute efficiencies). Daimler/Chrysler, Ford, General Motors, Mitsubishi and Volkswagen are less than one indicating inferior performance. We also note that except for one or two years, BMW, Mazda, Nissan and Toyota have DEA efficiency score of $100 \%$ or 1 . The results also indicate that BMW, Nissan, Mazda, and Toyota are improving their performance of operations relative to the others, while Daimler/Chrysler, Ford, General Motors, Mitsubishi and Volkswagen perform relatively less well in the sample period.

We use alternate specifications of the inputs and outputs to judge how sensitive our ranking is to different combinations of variables. Most of the alternate combinations we explore give a similar relative ranking although the efficiencies exhibit greater variability. One of these combinations included the outputs of change in revenue, satisfaction, and return on assets, and the inputs of costs of goods sold (COGS), selling, general and administrative expenses (SG\&A) and mean repair history scores. The only difference in the results from those shown above, is that BMW's performance is lower while Volkswagen's performance is slightly higher. In the next section, we augment the DEA analysis with a qualitative examination of Skinner's model.

\section{SKINNER'S OPERATIONS STRATEGY METRICS}

Skinner (1985) specifies cost, quality, reliability, and service as the cornerstone of success for manufacturing companies. In addition, the product should conform to all four metrics (i.e., dimensions) and not excel in any single metric in order to provide the best value to the customer. The best value can be specified as the integration of all these metrics into the product in an efficient manner to serve the customer's needs. The result is a pyramid consisting of all four dimensions with each side representing a metric. We collect a variety of information to execute Skinner's dimensions, including retail prices, reliability, and customer satisfaction from Consumer Reports. We expect, all other things being equal, that revenue growth and ultimately U. S. market share will be linked to improvements in efficiency and quality.

A more detailed listing of Skinner's criteria to judge the performance of manufacturing firms includes cost, quality, reliability, return on investment, customer lead times, flexibility to introduce new products, and appropriate social criteria. As stated above, Skinner recommends that firms should seek to excel in all dimensions to provide the best value to the customer. We explore some of these aspects such as cost, reliability, and consumer satisfaction outside the DEA framework. Specifically, we compare retail price versus satisfaction, satisfaction and reliability, and change in market share over the sample period. 
We obtained the retail prices of sample cars from Consumer Reports (1998-2003) and computed their median prices. The details are presented in Tables $3 \mathrm{a}, 3 \mathrm{~b}$, and 3c, Appendix B. We also downloaded quality reports and reliability data from Consumer Reports (1998-2003). Figures 2a, 2b and 2c plot the median prices against quality (consumer satisfaction). The charts are oriented such that the best position from the consumer's standpoint is the southeast corner, that is, the highest quality for the lowest price. Figure 2a reveals a clustering of firms (Honda and Toyota) at a quality level of 4 (with 5 defined as the "best") and a median price of approximately $\$ 15,000$ and another cluster of firms with compact cars (Dodge, Nissan, Ford and Chevrolet) at a quality of 1 and a median price of approximately $\$ 15,000$. Figure $2 \mathrm{~b}$ represents quality vs. price for mid-sized vehicles and also has two large clusters, with two firms (Honda and Toyota) at a quality of 5 and an approximate average price of $\$ 22,000$ and seven models (Chevrolet, Pontiac, Ford, Chrysler, Mercury, Dodge, Oldsmobile) at a quality of 2 and an approximate price of $\$ 20,000$ - $\$ 25,000$. Buick, Mazda and Nissan are also in the same price range with a quality of 3. BMW with a price tag of $\$ 38,500$ has a quality rating 5 .

Figure 2c, our third chart, plots quality versus prices for family-sized vehicles. Volkswagen has no entry in this class and we include two from General Motors. Honda and Toyota are both in the lower right hand part of the chart along with one of the General Motors vehicles. Considering all three model sizes, it appears that Honda and Toyota are consistently in the preferred southeast corner. We believe this suggests they deliver the highest quality at the lowest price, which is an important component of Skinner's performance model.

Table 3: Summary of Customer Satisfaction for years 1998-2003

The sample firms are: Audi (A), BMW (B), Daimler/Chrysler (D), Ford (F), GM (G), Honda (H), Mazda (Ma), Mitsubishi (Mi), Nissan (N), Toyota (T) and Volkswagen (V).

\begin{tabular}{|c|c|c|c|c|c|c|}
\hline Company & $\begin{array}{c}\mathbf{2 0 0 3} \\
\text { Satisfaction }\end{array}$ & $\begin{array}{c}\mathbf{2 0 0 2} \\
\text { Satisfaction }\end{array}$ & $\begin{array}{c}\mathbf{2 0 0 1} \\
\text { Satisfaction }\end{array}$ & $\begin{array}{c}\mathbf{2 0 0 0} \\
\text { Satisfaction }\end{array}$ & $\begin{array}{c}\mathbf{1 9 9 9} \\
\text { Satisfaction }\end{array}$ & $\begin{array}{c}\mathbf{1 9 9 8} \\
\text { Satisfaction }\end{array}$ \\
\hline $\mathrm{A}$ & 3.5 & 4.5 & 4.5 & 4.5 & 5 & 4 \\
\hline $\mathrm{B}$ & 4.83 & 4.75 & 4.83 & 5 & 4.5 & 3 \\
\hline $\mathrm{D}$ & 2.56 & 3 & 3 & 3 & 2.5 & 2.5 \\
\hline $\mathrm{F}$ & 2.43 & 2.07 & 3 & 3 & 3 & 3.25 \\
\hline $\mathrm{G}$ & 2.48 & 2.47 & 3 & 3 & 3 & 3 \\
\hline $\mathrm{H}$ & 5 & 5 & 5 & 5 & 6 & 5 \\
\hline $\mathrm{Ma}$ & 3 & 5 & 3 & 2.5 & 3 & 4 \\
\hline $\mathrm{Mi}$ & 3 & 3 & 2 & 3 & 3 & 2 \\
\hline $\mathrm{N}$ & 3 & 3 & 2.5 & 4 & 4 & 4 \\
\hline $\mathrm{T}$ & 4.5 & 5 & 4.5 & 5 & 4 & 5 \\
\hline $\mathrm{V}$ & 4 & 3.5 & 4.5 & 5 & 5 & 5 \\
\hline
\end{tabular}

We use the consumer satisfaction scores reported in Consumer Reports, which is based on questionnaires they distribute and collect. Their scale from 1 to 5 (with 5 being the highest rating) is based on a response to the question "Would you buy this particular vehicle again?"

The sample firms are: Audi (A), BMW (B), Daimler/Chrysler (D), Ford (F), GM (G), Honda (H), Mazda (Ma), Mitsubishi (Mi), Nissan (N), Toyota (T) and Volkswagen (V). Quality is Consumer Satisfaction. 
Figure 2a: Quality Vs. Small Car Prices

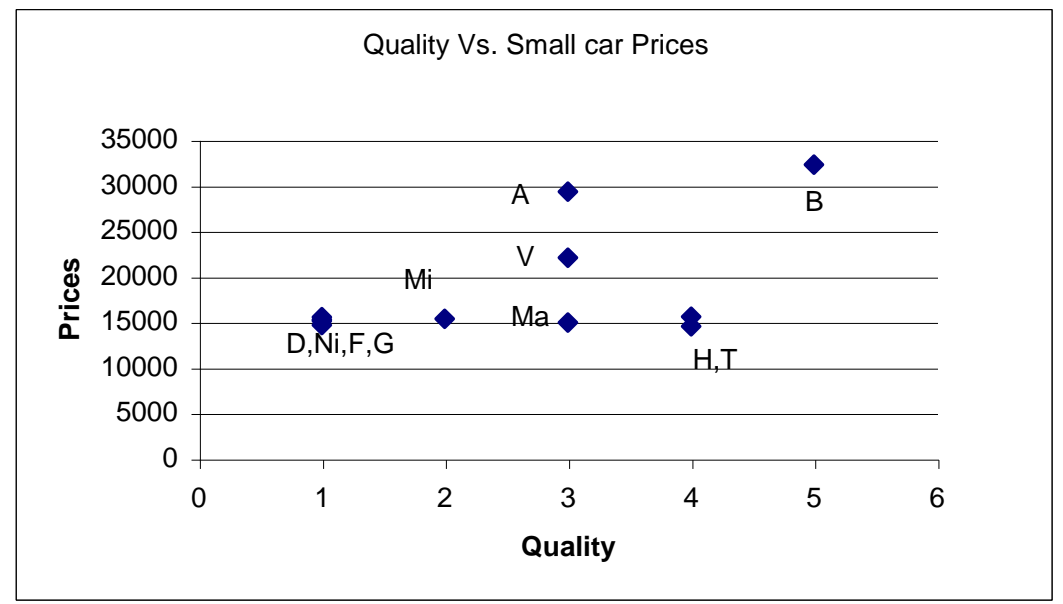

Figure 2b: Quality Vs. Mid sized Car prices

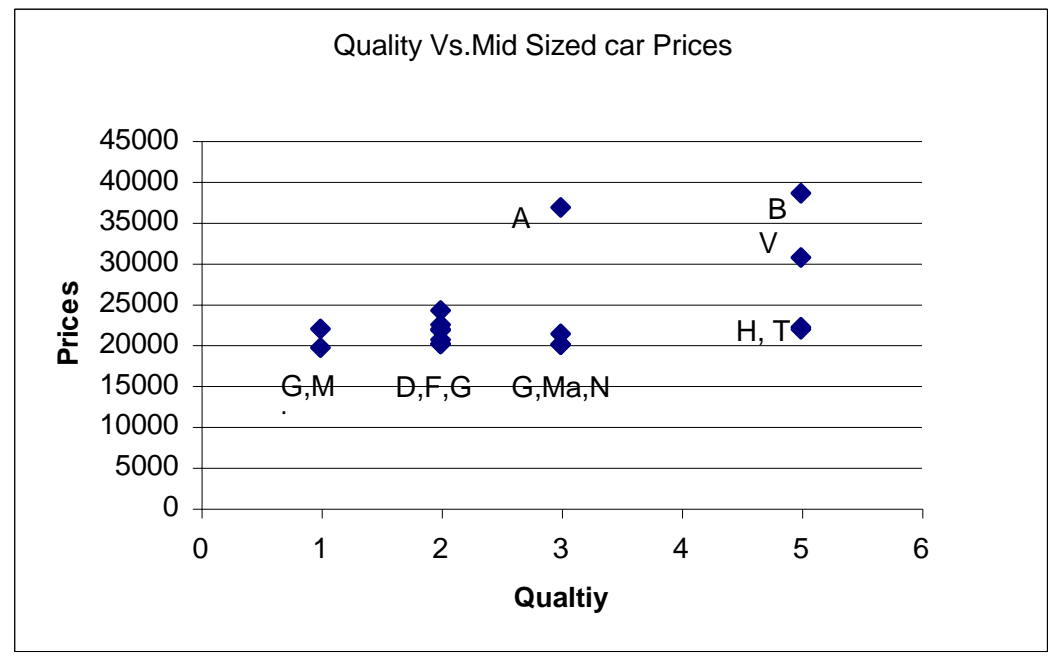

Figure 2c: Quality Vs. Family Car Prices

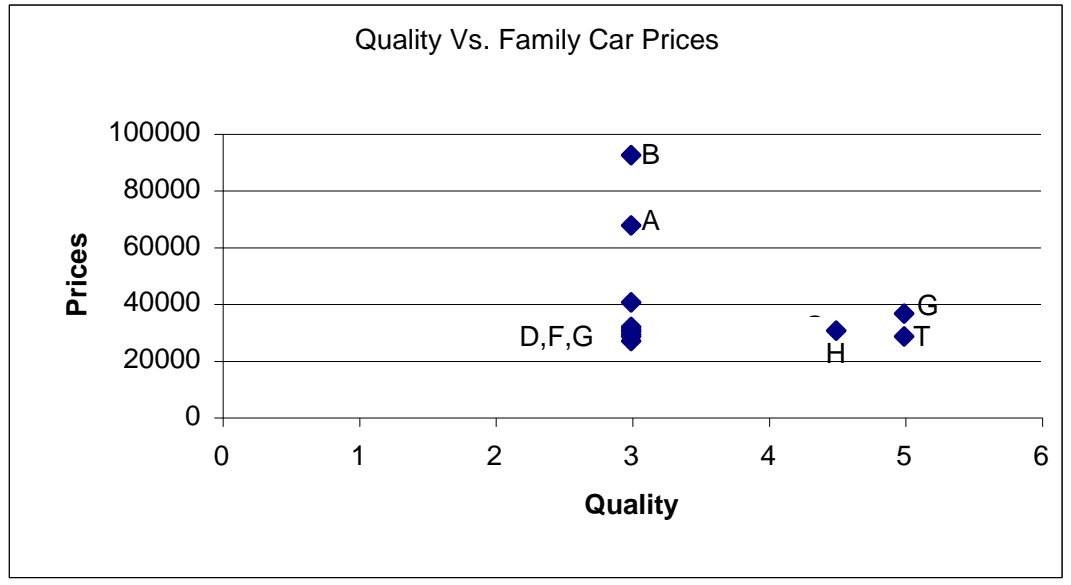


To further examine the relationship between Skinner's components, we use the repair history/mechanical quality measure from Consumer Reports as a proxy for Skinner's reliability component and present the information in Table 4. With some exceptions, the reliability scores are fairly well correlated with the satisfaction scores reported above. Audi, BMW and Volkswagen have much lower reliability than expected considering their high customer satisfaction. Also, Nissan has a repair history that would imply slightly higher satisfaction than what they actually achieve. This suggests that satisfaction is not determined solely by reliability, but rather is made up of a number of considerations that may include the price-to-quality ratio, advertising inducements, or prior experience with the brand. This is consistent with Ginter, et al. (1987) findings that the association between used-car price and quality (as measured by reliability) is weak. Their findings, as do ours, suggests that consumer choice is more complex than a straightforward connection between price and quality.

Table 4: Mean Scores for Vehicle Reliability Data for years 1998-2003

The sample firms are: Audi (A), BMW (B), Daimler/Chrysler (D), Ford (F), GM (G), Honda (H), Mazda (Ma), Mitsubishi (Mi), Nissan (N), Toyota (T) and Volkswagen (V).

\begin{tabular}{|c|c|c|c|c|c|c|}
\hline $\begin{array}{c}\text { Automotive } \\
\text { Companies }\end{array}$ & $\begin{array}{c}\mathbf{2 0 0 3} \\
\text { Reliability }\end{array}$ & $\begin{array}{c}\mathbf{2 0 0 2} \\
\text { Reliability }\end{array}$ & $\begin{array}{c}\mathbf{2 0 0 1} \\
\text { Reliability }\end{array}$ & $\begin{array}{c}\mathbf{2 0 0 0} \\
\text { Reliability }\end{array}$ & $\begin{array}{c}\mathbf{1 9 9 9} \\
\text { Reliability }\end{array}$ & $\begin{array}{c}\mathbf{1 9 9 8} \\
\text { Reliability }\end{array}$ \\
\hline $\mathrm{A}$ & 2.33 & 1.5 & 2.5 & 3.5 & 3.5 & 4 \\
\hline $\mathrm{B}$ & 2 & 3 & 4 & 3.5 & 3.33 & 3 \\
\hline $\mathrm{D}$ & 2.5 & 3 & 2 & 2.29 & 2.5 & 2.5 \\
\hline $\mathrm{F}$ & 2.14 & 2.07 & 3 & 3 & 3 & 3 \\
\hline $\mathrm{G}$ & 2.21 & 2.03 & 2.25 & 2 & 2.19 & 2.12 \\
\hline $\mathrm{H}$ & 4.5 & 5 & 5 & 5 & 5 & 5 \\
\hline $\mathrm{Ma}$ & 4 & 5 & 4.2 & 3.6 & 4 & 4.5 \\
\hline $\mathrm{Mi}$ & 3 & 3 & 3 & 3 & 1 & N/A \\
\hline $\mathrm{N}$ & 4 & 4 & 4 & 4 & 4 & N/A \\
\hline $\mathrm{T}$ & 5 & 5 & 4.17 & 5 & 5 & N/A \\
\hline $\mathrm{V}$ & 1.75 & 3 & 2.5 & 3 & & 3 \\
\hline
\end{tabular}

Our summary comparison is the change in the firm's market share over the sample period. We collect the market shares of these global companies from the Market Share Reporter (edited by Lazich) for years 1998 through 2003 (Table 5). One firm Audi, was not reported because it was acquired at the end of the sample period, and its historical information was not available.

Table 5: U. S. Market (Units Of Cars As A Percentage Of Total Cars Sold)

The sample firms are: Audi (A), BMW (B), Daimler/Chrysler (D), Ford (F), GM (G), Honda (H), Mazda (Ma), Mitsubishi (Mi), Nissan (N), Toyota (T) and Volkswagen (V).

\begin{tabular}{|c|c|c|c|c|c|c|}
\hline Company & Year 2003 & Year 2002 & Year 2001 & Year 2000 & Year 1999 & Year 1998 \\
\hline $\mathrm{D}$ & 12.8 & 13.1 & 13.2 & 14.5 & 16.7 & 16.1 \\
\hline $\mathrm{F}$ & 19.5 & 20.2 & 21.9 & 23 & 25.1 & 24.9 \\
\hline $\mathrm{G}$ & 28 & 28.4 & 28.1 & 28.1 & 29.4 & 29.2 \\
\hline $\mathrm{H}$ & 8.1 & 7.4 & 7 & 6.7 & 6.4 & 6.5 \\
\hline $\mathrm{Ma}$ & 1.6 & 1.5 & & 1.5 & & 1.5 \\
\hline $\mathrm{Mi}$ & 1.5 & 2 & 2 & 1.8 & & 4.2 \\
\hline $\mathrm{N}$ & 4.8 & 4.4 & 4.1 & 4.3 & 4 & 4 \\
\hline $\mathrm{T}$ & 11.2 & 10.4 & 10.1 & 9.3 & 8.7 & 8.7 \\
\hline $\mathrm{V}$ & 2.3 & 2.5 & 2.1 & 2 & 2.2 & 1.4 \\
\hline
\end{tabular}


Market shares do not add up to 100 due to the exclusion of some smaller firms. One percent of gain or loss translates to 166,650 units of automobiles per year (Auto Industry Report, 2004).

During 2003, Toyota's market share increased from 10.4 to 11.2 percent, Honda's market share increased from 7.4 to 8.1 percent while U.S. automaker's market share as a group declined by almost a total of 3.4 percent (Mergent Online, 2003). Most of the other automakers experienced flat or slightly declining market shares. Honda and Toyota improved the most. Overall, the market share of Honda, Nissan, and Toyota increased while GM, Ford, Daimler/Chrysler and Mitsubishi decreased, which suggests that Skinner's model linking quality and value to increases in revenues is supported. One important consequence of the loss of market share for domestic manufacturers is the concomitant loss of employment. We construct a analysis of the loss in employment shown in Figure 4.

To supplement the market share figures above, we calculated the change in revenues using data from Mergent Online for the six-year period. The results can be found in Table 6. The raw revenue numbers in millions are shown for each firm and we calculate a total period change by taking the simple percentage increase. The largest improvement in revenue was achieved by Audi, Honda, Mazda, and Toyota (by around 50 percent) while others decreased or increased in varying degrees.

Table 6: Revenues and Overall Growth Rate for years 1998-2003

The sample firms are: Audi (A), BMW (B), Daimler/Chrysler (D), Ford (F), GM (G), Honda (H), Mazda (Ma), Mitsubishi (Mi), Nissan (N), Toyota (T) and Volkswagen (V).

\begin{tabular}{|c|c|c|c|c|c|c|c|}
\hline Company & $\mathbf{2 0 0 3}$ & $\mathbf{2 0 0 2}$ & $\mathbf{2 0 0 1}$ & $\mathbf{2 0 0 0}$ & $\mathbf{1 9 9 9}$ & $\mathbf{1 9 9 8}$ & Yr03/Yr98 \\
\hline A & 23406 & 21925 & 19388 & 18732 & 15108 & 16061 & 1.457319 \\
\hline B & 51611 & 41014 & 33847 & 33235 & 34402 & 37249 & 1.385567 \\
\hline D & 169578 & 145096 & 134528 & 152641 & 149985 & 154615 & 1.096776 \\
\hline F & 138442 & 134425 & 131528 & 141230 & 136973 & 110496 & 1.252914 \\
\hline G & 185524 & 186763 & 177260 & 184632 & 176558 & 161315 & 1.150073 \\
\hline H & 76728 & 63772 & 55218 & 51064 & 59159 & 51718 & 1.483584 \\
\hline Ma & 27412 & 18916 & 15712 & 15925 & 20967 & 17074 & 1.605482 \\
\hline Mi & 23683 & 31079 & 24005 & 25886 & 32349 & 29155 & 0.812313 \\
\hline N & 69835 & 54629 & 46472 & 48108 & 57978 & 54614 & 1.278701 \\
\hline T & 162571 & 128434 & 113297 & 106053 & 124932 & 105817 & 1.536341 \\
\hline V & 108322 & 84340 & 77915 & 80318 & 74977 & 79203 & 1.36765 \\
\hline
\end{tabular}

As a reasonableness check, we use a parametric approach for the question concerning the link between profitability and quality. For the analyses above we collected 66 firm years of data on financial indicators and quality measures. We construct a regression model with return on assets (ROA) as the dependent variable and four independent variables including satisfaction, reliability, change in revenue, and total revenues (to represent firm size). Appendix B, Figure 5 exhibits that the overall model is significant with an F value of 6.27 (p-value of .0003) and an adjusted $\mathrm{R}^{2}$ of .2536 , and that satisfaction is significantly associated with ROA ( $\mathrm{p}$ value $=.045$ ). However, our reliability measure was not significantly associated with ROA. Diagnostic tests (not tabled here) indicate that the results are not due to serial correlation (we have 6 years of data for each firm) or multi-collinearity among the explanatory variables.

\section{SUMMARY AND CONCLUSIONS}

We use the DEA methodology along with other qualitative and quantitative measures to examine the performance of the automotive industry. Using annualized financial and consumer satisfaction data for the period 1998 to 2003, we present empirical evidence that quality, as measured by consumer satisfaction and vehicle reliability reported in Consumer Reports, is associated with profits and changes in market share for automotive firms. Our 
evidence suggests that firms with high (low) quality, on average, have higher (lower) profitability and higher (lower) increases in market share for the sample period.

Industry change experts, such as Wickham Skinner, have long espoused the benefits firms can derive by concentrating on delivering value to the customer. We provide empirical evidence that supports Skinner's (and others such as Deming's) assertions. The implication is that attention to customer satisfaction and quality will lead to better firm financial performance.

Although we focus on the new car market, we believe our results imply that any manufacturer can benefit from attention to customer satisfaction. As cited in earlier research by Ginter, et al. (1987), the relationship between price and quality is complex and so the relationship between firm performance and a firm's actions to deliver value to the customer are unlikely to be straightforward. High quality does not necessarily lead to better firm financial performance through the firm's ability to charge higher prices at point of purchase. More likely is the notion that a high quality product offered at a moderate price (the southeast corner in the price/satisfaction charts) leads to higher market share which leads to higher firm profitability.

For the automotive industry in particular, we find that by using both quantitative and qualitative methods, we can rank the firms in three groups. Honda and Toyota excel in all categories and are the top performers. Audi, GM, Mazda, and Nissan perform somewhat less well and constitute a middle group, while BMW, Daimler/Chrysler, Ford, Mitsubishi and Volkswagen are in the relatively low performing group. This result is noted, more informally, in the popular press. In a Business Week magazine article, Bremmer and Dawson (2003) ask: "Can Anything Stop Toyota?" We believe that their question is predicated on the attention that Toyota and Honda appear to pay to delivering value to their customers. Future research could explore the relationship of product quality, price and firm performance in other industries. In addition, our findings imply that future research should explore the possible obstacles to improving quality faced by the U.S. auto manufacturers and how to eliminate them.

Acknowledgement: We thank the unknown reviewers at JABR, and the suggestions made by participants when this paper was presented at the 2004 POMS conference. In addition, we thank professors Mark Higgins and Shaw Chen at the University of Rhode Island for their helpful comments.

\section{REFERENCES}

1. Ali, A. I. and L. M. Seiford (1993), The Mathematical Programming Approach to Efficiency Analysis in Fried, H. O, C. A. Knox Levell and S. S. Schmidt, The Measurement of Productive efficiency: Theory and Applications, Oxford University Press.

2. $\quad$ Bremmer, B and C. Dawson (2003), Can Anything Stop Toyota, Business Week, November 17, 116-122.

3. Brown, J. R., and C. T. Ragsdale (2002), The Competitive Market Efficiency of Hotel Brands: An Application of Data Envelopment Analysis, Journal of Hospitality \& Tourism Research, 26, 4, 332-360.

4. Chapman, R. A. (1998), Using Data Envelopment Analysis to assess performance of manufacturing extension centers, U. S. department of Commerce, Technology Administration, National Institute of Standards and Technology, Office of Applied Economics, Building and Fire Research Laboratory.

5. Charnes, A, W. W. Cooper, and E. Rhodes (1978), Measuring the Efficiency of Decision Making Units, European Journal of Operational Research, 2, 429-444.

6. Charnes, A, W.W. Cooper, A.Y.Lewin, and L. M. Seiford (1994), Data Envelopment Analysis: Theory, Methodology, and Applications, Kluwer Academic Publishers, Boston.

7. Consumer Reports, a monthly publication of Consumer Union of U. S., Inc. Yonkers, NY 10703.

8. Ginter, J.L., M.A. Young, and P.R. Dickson (1987), A Market Efficiency Study of Used Car Reliability and Prices, The Journal of Consumer Affairs, 21, 2, 258-276.

9. Government Publications site (2002): http://www.bea.gov/bea/dn/dpga.txt

10. Lazich, R. S. (1997-2002), Market Share Reporter, Thomson/Gale Publishing

11. Lothgren, M and M. Tambour (1999), Productivity and customer satisfaction in Swedish pharmacies: A DEA network Model, European Journal of Operational Research, 115, 3, 449-458. 
12. Mergent Online (1998-2003), online version of Moody's Manuals covers financial data of over 10,000 U. S. publicly traded companies and selected international companies.

13. Mitra, A. (1993), Fundamentals of Quality Control and Improvement, Macmillan Publishing Company, New York.

14. Petroni, A., and Bevilacqua (2002), Identifying manufacturing flexibility best practices in small and medium enterprises, International Journal of Operations \& Production Management, 22, 8, 929-947

15. Ragsdale, C. T. (2004), Spread Sheet Modeling and Decision Analysis, Southwestern Publications, USA

16. Skinner, W. (1985), Manufacturing: The Formidable Competitive Weapon, Wiley, New York.

17. Soteriou, A. C, and Y. Stavrinides (1997), An Internal customer Service quality data envelopment analysis model for bank branches, Journal of Operations \& Production Management, 17, 8, 780-789.

18. Yin, R., (2002), DEA: A New Methodology for Evaluating the Performance of Forest Products Procedures, Forest Products Journal, 48, 1, 29-34

\section{APPENDIX A}

\section{The Data Envelopment Analysis Model}

Using DEA analysis, the efficiency of a unit $\mathrm{i}$ is defined as follows:

Efficiency of unit $\mathrm{i}=\frac{\text { Weighted sum of unit } i^{\prime} \text { s outputs }}{\text { Weighted sum of unit } i^{\prime} \text { s inputs }}=\frac{\sum_{j=1}^{n_{0}} O_{i j} u_{j}}{\sum_{j=1}^{n_{1}} I_{i j} v_{j}}$

Where $\mathrm{O}_{i j}$ represents the value of unit $\mathrm{i}$ on output $\mathrm{j}, \mathrm{I}_{\mathrm{ij}}$ represents the value of unit $\mathrm{i}$ on input $\mathrm{j}$, $\mathrm{u}_{\mathrm{j}}$ is a nonnegative weight associated to output $\mathrm{j}, \mathrm{v}_{\mathrm{j}}$ is a nonnegative weight associated to the input $\mathrm{j}, \mathrm{n}_{0}$ specify the number of output variables and $n_{1}$ is the number of input variables. The values of inputs and outputs are known. Therefore, DEA problem consists of maximizing the weighted sum of outputs when every input and output values are known and specified. This amounts to determining the values of decision variables $\mathrm{u}_{\mathrm{j}}$ and $\mathrm{v}_{\mathrm{j}}$ in order to maximize the output.

\section{Defining the Objective Function}

We want to maximize the output from each unit subject constraints, that is,

MAX: $\quad \sum_{j=1}^{n_{0}} O_{i j} u_{j}$

\section{Defining the Constraints}

The weighted sum of outputs cannot exceed the weighted sum of inputs, that is,

$$
\sum_{j=1}^{n_{0}} O_{k j} u_{j} \leq \sum_{j=1}^{n_{1}} I_{k j} v_{j}, \text { for } \mathrm{k}=1 \text { to number of units } \mathrm{j} \text {. }
$$

Or equivalently

$\sum_{j=1}^{n_{0}} O_{k j} u_{j}-\sum_{j=1}^{n_{1}} I_{k j} v_{j} \leq 0$, for $\mathrm{k}=1$ to number of units $\mathrm{j}$ 
To prevent unbounded solutions, we impose the sum of the weighted inputs and outputs for the unit $\mathrm{i}$ equal to one or weighted sum of inputs equal one which automatically imposes a constraint on weighted sum of output as one.

$$
\sum_{j=1}^{n_{1}} I_{i j} v_{j}=1 \quad \text { The maximum DEA efficiency will be } 1 \text { or } 100 \%
$$

In their efficiency study of banks, Soteriou and Stanrinides (1997) point out that efficiency can be measured as technical efficiency (productivity), price efficiency or some combination of the two. Technical efficiency is the use of the various factors of production such as labor, materials, and overhead as inputs. In contrast, price efficiency is more concerned with the reaction of consumers and their perceptions of value. These different ways to specify the model can also be thought of as production-based efficiency or market-based efficiency.

Chapman (1998) examined annual data from 51 small and medium-sized companies over a five-year period using envelopment analysis to assess the relative technical performance of Manufacturing Extension Partnership (MEP) companies.

A study on wood products by Yin (2001) and a study on small and medium manufacturers by Petroni and Bevilacqua (2002), focus on the comparison of technical efficiency at the manufacturing plant level. The study of hotel brands by Brown and Ragsdale (2002) is primarily a market-based efficiency study. The two types of efficiency, price and technical efficiency, can be combined in a single measure, which is alternately called economic efficiency or overall efficiency. In their study of pharmacies, Lothgren and Tambour (1999) use both production-type measures and market-based measures that provide a good example of overall efficiency.

\section{APPENDIX B}

Table 3a: Compact Car Prices Vs. Quality

\begin{tabular}{|c|c|c|c|c|}
\hline & Prices & Prices & Consumer & Prices \\
\hline Sample Compact Cars & Low & High & Satisfaction & Median \\
\hline Audi A4 & 25100 & 33490 & 3 & 29295 \\
\hline BMW 325 & 27800 & 36700 & 1 & 32250 \\
\hline Chevy Cavalier & 14030 & 17030 & 1 & 15530 \\
\hline Dodge Neon & 13030 & 17180 & 1 & 15105 \\
\hline Ford Focus & 12820 & 17625 & 4 & 15223 \\
\hline Honda Civic & 13010 & 18110 & 3 & 15560 \\
\hline Mazda Protégé & 1360 & 16140 & 2 & 14910 \\
\hline Mitsubishi Lancer & 14047 & 16657 & 1 & 15352 \\
\hline Nissan Sentra & 12099 & 17199 & 4 & 14649 \\
\hline Toyota Carolla & 13570 & 15480 & 3 & 14525 \\
\hline VW Jetta & 17100 & 26940 & & 22020 \\
\hline
\end{tabular}


Table 3b: Mid- sized Prices Vs. Quality

\begin{tabular}{|c|c|c|c|c|}
\hline Sample Mid Size Cars & Prices Low & Prices High & Consumer Satisfaction & Prices Median \\
\hline Audi A6 & 35850 & 37600 & 3 & 36725 \\
\hline BMW 525 & 37600 & 39300 & 5 & 38450 \\
\hline Dodge Stratus & 18080 & 21950 & 2 & 20015 \\
\hline Chrysler Sebring & 20655 & 22930 & 2 & 21793 \\
\hline Ford Taurus & 19630 & 23750 & 2 & 22375 \\
\hline Mercury Sable & 20625 & 24125 & 3 & 21235 \\
\hline Buick Century & 21235 & 21235 & 1 & 20510 \\
\hline Chevy Malibu & 14770 & 24370 & 2 & 20005 \\
\hline Olds Alero & 18085 & 22935 & 2 & 24085 \\
\hline Pontiac GrandAm & 17070 & 22940 & 2 & 21800 \\
\hline Pontiac GrandPrix & 21760 & 26410 & 5 & 19935 \\
\hline Honda Accord & 15800 & 27800 & 3 & 21847 \\
\hline Mazda 6 Series & 18650 & 21220 & 1 & 19949 \\
\hline Mitsubishi Galant & 17997 & 25697 & 3 & 22045 \\
\hline Nissan Altima & 16749 & 23149 & 5 & 30575 \\
\hline Toyota Camry & 19045 & 25045 & 5 & 2 \\
\hline VW Passat & 21750 & 39400 & & 2 \\
\hline
\end{tabular}

Table 3c: Family sized Car Prices Vs. Quality

\begin{tabular}{|c|c|c|c|c|}
\hline $\begin{array}{c}\text { Sample Family size } \\
\text { Cars }\end{array}$ & Prices Low & Prices High & Consumer Satisfaction & Prices Median \\
\hline Acura TL & 28980 & 31330 & 4.5 & 30155 \\
\hline Audi A8 & 62200 & 72500 & 3 & 67350 \\
\hline BMW 7 Series & 68500 & 115800 & 3 & 92150 \\
\hline Buick LaSabre & 25285 & 30985 & 3 & 28135 \\
\hline Chevrolet Avalanche & 37705 & 34705 & 5 & 36205 \\
\hline Chrysler 300M & 29185 & 32165 & 3 & 26545 \\
\hline Ford Crown Victoria & 23595 & 29495 & 3 & 28860 \\
\hline Mercury Grand Marquis & 23950 & 33770 & 3 & 29940 \\
\hline Pontiac Bonneville & 26265 & 33615 & 5 & 3125 \\
\hline Toyota Avalon & 25845 & 30405 & 3 & 31598 \\
\hline Volvo S60 & 26370 & 36825 & 3 & 40195 \\
\hline Volvo S80 & 36455 & 43935 & & \\
\hline
\end{tabular}

Table 4: Cmputing Possible Number of U.S. Jobs Lost

\begin{tabular}{|c|c|c|c|c|c|c|c|}
\hline Company & $\begin{array}{c}\text { Units Sold in } \\
\mathbf{2 0 0 2}\end{array}$ & $\begin{array}{c}\text { Units Sold } \\
\text { in 2003 }\end{array}$ & $\begin{array}{c}\text { Units of Lost } \\
\text { Sales }\end{array}$ & hours/unit & Toal Hrs. & Hrs/Year & $\begin{array}{c}\text { Possible } \\
\text { Jobs Lost }\end{array}$ \\
\hline GM & $4,782,212$ & $4,666,868$ & 115,344 & 24.44 & 2819007.36 & 2400 & 1175 \\
\hline Ford & $3,403,729$ & $3,247,671$ & 156,058 & 26.14 & 4079356.12 & 2400 & 1700 \\
\hline DMC & $2,205,446$ & $2,127,451$ & 77,995 & 28.04 & 2186979.8 & 2400 & 911 \\
\cline { 5 - 8 } & & & \multicolumn{2}{|c|}{ Total Jobs Lost } & 3786 \\
\hline
\end{tabular}


Table 5: Regression Analysis Of The Impact Of Customer

Satisfaction On Return On Investment For Automobile Manufacturers

\begin{tabular}{|c|c|c|c|}
\hline Variable & Coefficient & t- value & P-value \\
\hline Intercept & -0.1037 & -2.89 & 0.005 \\
\hline Satisfaction & 0.0164 & 2.04 & 0.046 \\
\hline Reliability & 0.0117 & 1.44 & 0.155 \\
\hline Revenue Change & 0.1395 & 3.04 & 0.004 \\
\hline Total Revenue & 0.0001 & 2.50 & 0.015 \\
\hline Observations 66, Model F-value 6.27, Adjusted $\mathrm{R}^{2}$ of .254 & \\
\hline
\end{tabular}

